\section{Characterization of Some Self- compatible Almonds. II. Flower Phenology and Morphology}

\author{
D. Bernad and R. Socias i Company \\ Unidad de Fruticultura, Servicio de Investigación Agraria, Diputación General \\ de Aragón, Apartado 727, 50080 Zaragoza, Spain
}

Additional index words. Prunus amygdalus = Prunus dulcis, breeding, temperature, autogamy

\begin{abstract}
Bloom evolution and flower quality were studied in 10 almond [ Prunus amygdalus Batsch syn. P. dulcis (Mill.) D.A. Webb] selections of the Zaragoza breeding program. The opening of individual flowers followed a normal distribution, with deviations reflecting temperature differences during the bloom period. The first open flowers are of better quality than later ones and may contribute more to fruit set. The relative stigma-anther position reflected the possibility of natural autogamy in three of the 10 selections. Natural autogamy might allow single-cultivar orchards without the need for pollinating insects.
\end{abstract}

Almond has traditionally been the first temperate fruit tree species to bloom. As a result, in most almond-growing regions, flowering takes place when the weather conditions are not well suited for pollination and fruit set. Temperatures are usually low, with frequent irradiation frosts that can reduce or even eliminate yields. Low temperatures and other unfavorable weather conditions (rain, wind) that are frequent during bloom can also reduce yields by interfering with pollinating insects, mainly honeybees.

Most almond breeding programs have focused on self-compatibility (Socias i Company, 1990). Other priorities include later bloom to have the flowers open when the weather conditions are more favorable. Selfcompatible cultivars, although they may not require identical conditions for pollination, also suffer from frosts. Temperature also affects the timing of bloom, especially duration and the dynamics of flower opening (Socias i Company, 1992).

Flower quality refers to the relative development of the pistil and the resulting ability to set fruit (Williams, 1965). In almond, ovary width has been related to ovule development and flower sterility or fertility (Socias i Company et al., 1976). Therefore, ovary width can be used as a morphological indicator of flower fertility or sterility.

As flower quality varies during the bloom period, specific periods during bloom, i.e.,

\footnotetext{
Received for publication 29 Mar. 1994. Accepted for publication 11 Oct. 1994. Part of a thesis submitted by D.B. in partial fulfillment for the Ingeniero Agrónomo degree at the Univ. Politécnica de Catalunya. We gratefully acknowledge the comments and help of A.J. Felipe. Research conducted under projects INIA 9567 and CICYT AGF 920294. The cost of publishing this paper was defrayed in part by the payment of page charges. Under posta regulations, this paper therefore must be hereby marked advertisement solely to indicate this fact.
}

those that coincide with the presence of fertile flowers, are more important for setting fruit than others (Socias i Company, 1983). The relative position of stigmas and anthers, which determines the possibility for natural selfpollination of the flowers and therefore natural autogamy (Godini et al., 1992; Weinbaum, 1985), plays an important role in flower quality of self-compatible cultivars.

The objective of the present work was to evaluate 10 selections of the Zaragoza breeding program (Felipe and Socias i Company, 1985) previously selected because of their good nut and kernel traits. The specific purpose was to assess flower quality during the bloom period to ascertain when fertile flowers are present; also of interest was the position of the stigma in relation to the anthers to complement the data on self-compatibility of these selections (Ben-Njima and Socias i Company, 1995).

\section{Materials and Methods}

The 10 selections studied have been described by Ben-Njima and Socias i Company (1995). A branch with a sufficient number of flower buds was chosen for each selection. During the 1990 and 1991 bloom periods, all open flowers on each branch were collected every morning around 9:00 AM. As flowers usually do not open at night due to lower temperatures, the figures represent the flowers opened during the previous $24 \mathrm{~h}$. The flowers were examined and the following distinctions were established: single (one flower from one bud), twin (two flowers from one bud), and coupled (two flowers with a single peduncle and fused calices from one bud); fertile or sterile, as determined by the ovary width, which usually reflects the presence or absence of well-developed ovules (Socias i Company, 1983; Socias i Company et al., 1976); single or double pistils, as some flowers have two pistils on their receptacle.

For analytical purposes, flowers with double pistils were considered fertile if at least one of the pistils was fertile, and coupled flowers were considered twin. Daily countings were summarized in four groups of several days. Then, the percentages of each type of flower, after angular transformation, were correlated with time.

Flower morphology was also determined in 1990 by examining 50 flowers of each selection collected at random around the tree at the beginning of bloom. The distances from the pistil base to (a) the stigma, (b) the highest anther, and (c) the lowest anther were measured. The value of (a) may not coincide with the pistil length, as some styles were curved in the upper part.

\section{Results and Discussion}

Bloom evolution. The objective of delaying the bloom period has been accomplished with these 10 selections. All bloom later than the two traditional Spanish cultivars ('Desmayo Largueta' and 'Marcona') and the main Californian cultivar ('Nonpareil') (Fig. 1). Selection E-5-7 was the earliest to bloom, with the others blooming at the same time or later than the recently released late-blooming cultivars from France ('Ferragnès') and Spain ('Guara'). Selection D-3-5 has consistently been the latest blooming almond of the germplasm collection at Zaragoza (Socias i Company and Felipe, 1992b).

The onset of the bloom season varied between 16 and 18 days for the different selections in 1990 and 1991 (Fig. 2). In 1990, the winter was mild and the bloom season was early compared to average blooming dates. Winter 1991 was cold and late blooming followed. In both years, however, chilling had been achieved as compared to the behavior of other almond cultivars (Tabuenca et al., 1972). Almond, like other temperate fruit and nut species, shows a clear influence of spring temperature on flower development. Low spring temperatures increase the length of the bloom period, while higher temperatures shorten it.

Daily flower opening as a percentage of the total number of flowers on the limb and the mean daily air temperatures during the bloom season of the two years are given in Fig. 2. A similar sequence of blooming was observed in both years. Only A-10-6 showed a small divergence. This general behavior was expected as based on other almond cultivars (Felipe, 1977). Bloom was shorter in 1991, probably due to slightly higher air temperatures, and as a result, higher percentages of opened flowers were recorded in single days. Selection A-102 showed the shortest bloom in both years. The late-blooming selections especially had longer bloom periods in 1990 due to the lower temperatures at the end of the bloom season.

Flower opening showed a pattern close to the normal distribution, as seen in almond (Hill et al., 1985; Socias i Company, 1992) and peach [Prunus persica (L.) Batsch.] (Blanco and Socias i Company, 1988). The normal distribution is probably the pattern of appearance of all the phenological phases of fruit trees (Severini et al., 1986). However, clear 

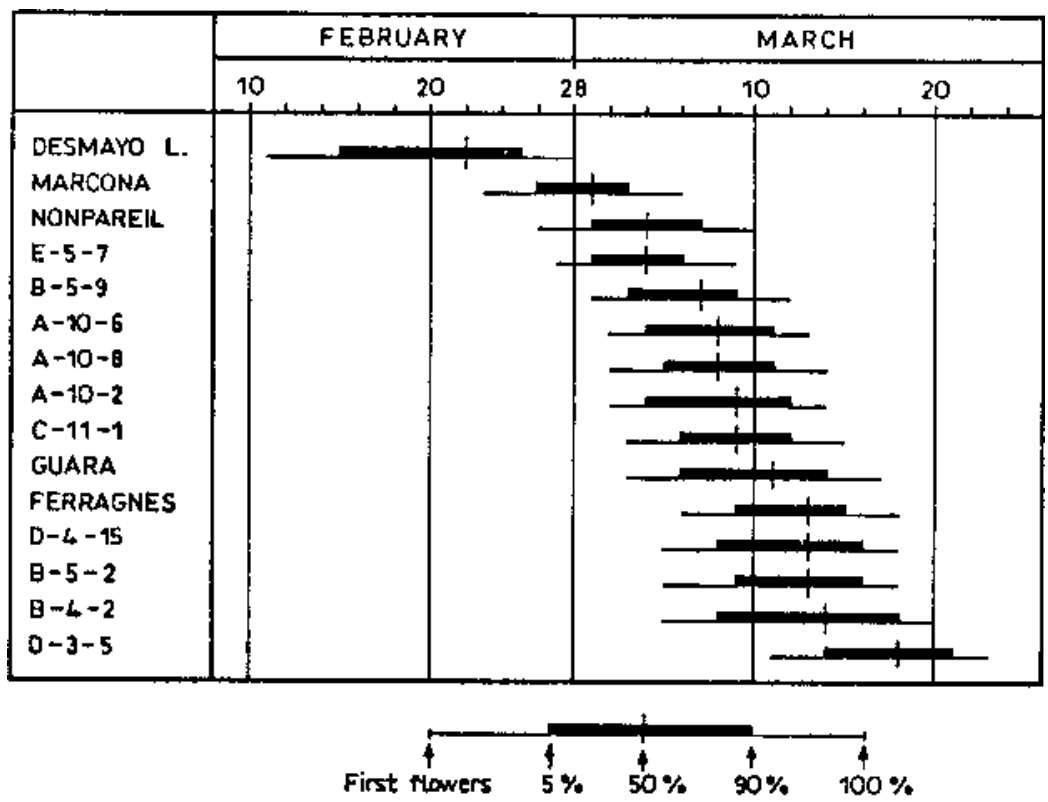

Fig. 1. Average blooming dates of the selections as compared to other almond cultivars (1988-92). Percentages indicate the proportion of flowers opened.

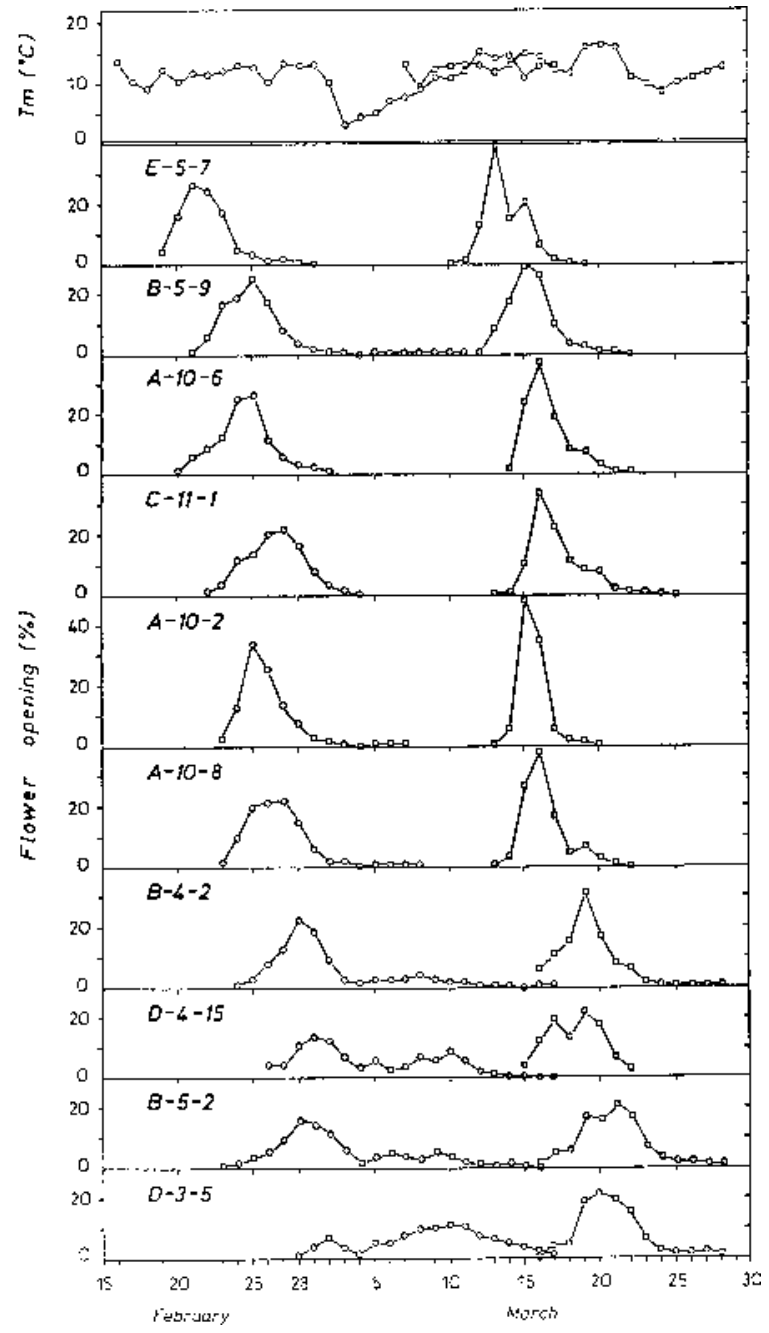

Fig. 2. Recorded flower emergence of 10 almond selections in 1990 (○) and 1991 ( $\square$ ). Each point represents the percentage of opened flowers collected early in the morning of that day, relative to the total number of flowers that opened on the limb. The upper panel shows the daily mean air temperatures during the two blooming seasons. divergences from the normal distribution were observed. A general deviation was the opening of a few flowers during the last days of the bloom, mainly for the late-blooming selections in 1990, which prolongs the blooming season, although not significantly, since these flowers are predominantly sterile and their development was probably retarded since the early stages of their initiation. This extension of the bloom period has been observed previously in almond (Socias i Company, 1992) and peach (Blanco and Socias i Company, 1988). This seasonal extension was also observed by Hill et al. (1985), but the quality of the lateopening flowers was not described.

More important is the deviation from the normal distribution observed for single days, which appeared to be related to temperature changes during the previous days. Sharp temperature decreases retarded bud development, thus reducing the number of opening flowers the following day. This delay was especially evident on 4 Mar. 1990, for the latest blooming selections, and on 16 Mar. 1991, for most of them. A similar delay related to a temperature decrease was reported earlier (Socias i Company, 1992). No such deviations were reported for peach (Blanco and Socias i Company, 1988), probably because temperature was quite constant during the bloom period. The same behavior can be deduced from the observations over several years by Hill et al. (1985), where decreases in the proportion of opening flowers were evident in various cultivars on the same day. This result may be a parallel response of these cultivars to possible temperature changes, although Hill et al. (1985) presented no temperatures for these bloom seasons.

The influence of temperature changes on flower emergence may depend on the blooming stage of each selection, which was probably the case for A-10-8 and B-5-2 on 26 Feb. 1990 , when blooming was slowed down by the temperature decrease of the day before, whereas the other selections did not reflect any significant effect.

Flower quality. A threat to flower quality is sterility, as indicated here by small, abortive pistils. The percentages of sterile and fertile flowers differed greatly among the selections and between years (Table 1). In all selections, the percentages were significantly different (at $P \leq 0.01$ ) within years. There is, however, a general characteristic in each selection: the low percentage of fertile flowers of D-3-5 in 1990 may be due to frost damage on 4-6 Mar., which made it difficult to identify the fertility type of its small flowers.

Differences, mainly among selections, also existed in the presence of twin flowers (Table 1). The effect of the year was important, but not in all the selections, as also observed for flower fertility. Three selections (A-10-2, A10-8, and D-3-5) did not differ in their percentages of twin flowers for the two years.

The relationship between date of flower opening in 1991 and percentage of sterile and twin flowers for four of the selections indicated that the first-opening flowers were predominantly single and fertile (Table 2). The 
Table 1. Percentages of the total of fertile and twin flowers for 10 almond selections during 2 years.

\begin{tabular}{|c|c|c|c|c|c|c|}
\hline \multirow[b]{2}{*}{ Selection } & \multicolumn{3}{|c|}{ Fertile flowers } & \multicolumn{3}{|c|}{ Twin flowers } \\
\hline & 1990 & 1991 & Mean & 1990 & 1991 & Mean \\
\hline A-10-2 & $85 d^{z}$ & $90 \mathrm{f}$ & $87 \mathrm{e}$ & $10 \mathrm{~b}$ & $10 \mathrm{~b}$ & $10 \mathrm{~b}$ \\
\hline A-10-6 & $83 d$ & $94 \mathrm{~g}$ & 89 ef & $5 \mathrm{a}$ & $12 \mathrm{~b}$ & $8 \mathrm{ab}$ \\
\hline A-10-8 & $59 \mathrm{~b}$ & $88 \mathrm{f}$ & $73 \mathrm{~d}$ & $44 \mathrm{e}$ & $47 \mathrm{f}$ & $46 \mathrm{e}$ \\
\hline B-4-2 & $85 \mathrm{~d}$ & $75 \mathrm{~d}$ & $80 \mathrm{de}$ & $11 \mathrm{~b}$ & $28 \mathrm{~d}$ & $19 \mathrm{c}$ \\
\hline B-5-2 & $74 \mathrm{c}$ & $62 \mathrm{~b}$ & $68 \mathrm{~d}$ & $26 \mathrm{~cd}$ & $37 \mathrm{e}$ & $32 \mathrm{~d}$ \\
\hline B-5-9 & 89 e & 85 e & $87 \mathrm{e}$ & $12 \mathrm{~b}$ & $21 \mathrm{c}$ & $16 \mathrm{bc}$ \\
\hline C-11-1 & $36 \mathrm{a}$ & $15 \mathrm{a}$ & $26 \mathrm{a}$ & $20 \mathrm{c}$ & $39 \mathrm{e}$ & $29 \mathrm{~d}$ \\
\hline D-3-5 & $43 \mathrm{a}$ & $70 \mathrm{c}$ & $56 \mathrm{c}$ & $3 \mathrm{a}$ & $5 \mathrm{a}$ & $4 \mathrm{a}$ \\
\hline D-4-15 & $53 \mathrm{~b}$ & $17 \mathrm{a}$ & $35 \mathrm{~b}$ & $33 \mathrm{~d}$ & $69 \mathrm{~g}$ & $51 \mathrm{e}$ \\
\hline E-5-7 & $95 \mathrm{f}$ & $90 \mathrm{f}$ & $93 \mathrm{f}$ & $5 \mathrm{a}$ & $18 \mathrm{c}$ & $12 \mathrm{~b}$ \\
\hline
\end{tabular}

${ }^{\mathrm{z}}$ Mean separation within columns by LSD test, $P \leq 0.01$.

Table 2. Relationship between date of almond flower opening and percentage of sterile and twin flowers (1991).

\begin{tabular}{|c|c|c|c|c|c|c|}
\hline \multirow[b]{2}{*}{ Selection } & \multirow{2}{*}{$\begin{array}{c}\text { Dates } \\
\text { (March) }\end{array}$} & \multicolumn{2}{|c|}{ Flower type (\%) } & \multicolumn{3}{|c|}{ Sterile flowers $(\%)$} \\
\hline & & Single & Twin & Single & Twin & Total \\
\hline \multirow[t]{4}{*}{ A-10-8 } & $13 / 15$ & 70.8 & 29.1 & 1.2 & 4.5 & 2.1 \\
\hline & $16 / 17$ & 49.6 & 50.3 & 2.1 & 7.6 & 4.8 \\
\hline & $18 / 19$ & 30.7 & 69.2 & 15.6 & 32.7 & 27.4 \\
\hline & $20 / 22$ & 20.8 & 79.1 & 44.4 & 47.1 & 46.5 \\
\hline$r^{2}$ & & \multicolumn{2}{|c|}{$0.98^{* *}$} & $0.91^{*}$ & $0.94^{*}$ & $0.95^{* *}$ \\
\hline \multirow[t]{4}{*}{ C-11-1 } & $13 / 15$ & 89.8 & 10.1 & 39.4 & 57.1 & 41.2 \\
\hline & $16 / 17$ & 60.1 & 39.8 & 78.4 & 92.6 & 83.7 \\
\hline & $18 / 19$ & 50.2 & 49.7 & 97.1 & 95.2 & 96.0 \\
\hline & $20 / 25$ & 33.2 & 66.7 & 98.3 & 99.1 & 98.9 \\
\hline$r^{2}$ & & \multicolumn{2}{|c|}{$0.93^{*}$} & $0.90^{*}$ & $0.84^{\mathrm{Ns}}$ & $0.90^{*}$ \\
\hline \multirow[t]{4}{*}{ D-3-5 } & $16 / 18$ & 98.8 & 1.1 & 2.7 & 50.0 & 3.2 \\
\hline & $19 / 21$ & 98.0 & 1.9 & 11.3 & 13.0 & 11.3 \\
\hline & $22 / 24$ & 89.7 & 10.2 & 59.7 & 73.1 & 61.1 \\
\hline & $25 / 28$ & 81.5 & 18.4 & 89.9 & 96.0 & 91.0 \\
\hline$r^{2}$ & & \multicolumn{2}{|c|}{$0.94^{* *}$} & $0.97^{* *}$ & $0.55^{\mathrm{Ns}}$ & $0.96^{* *}$ \\
\hline \multirow[t]{4}{*}{ E-5-7 } & $10 / 12$ & 95.6 & 4.3 & 7.2 & 0.0 & 6.9 \\
\hline & $13 / 14$ & 83.1 & 16.8 & 3.6 & 12.7 & 5.1 \\
\hline & $15 / 16$ & 72.6 & 27.3 & 9.1 & 23.2 & 12.9 \\
\hline & $17 / 19$ & 53.7 & 46.2 & 19.0 & 33.3 & 25.6 \\
\hline$r^{2}$ & & \multicolumn{2}{|c|}{$0.99^{* *}$} & $0.60^{\mathrm{Ns}}$ & $0.92^{*}$ & $0.79^{\mathrm{Ns}}$ \\
\hline
\end{tabular}

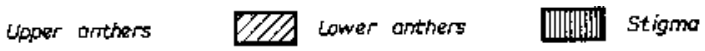

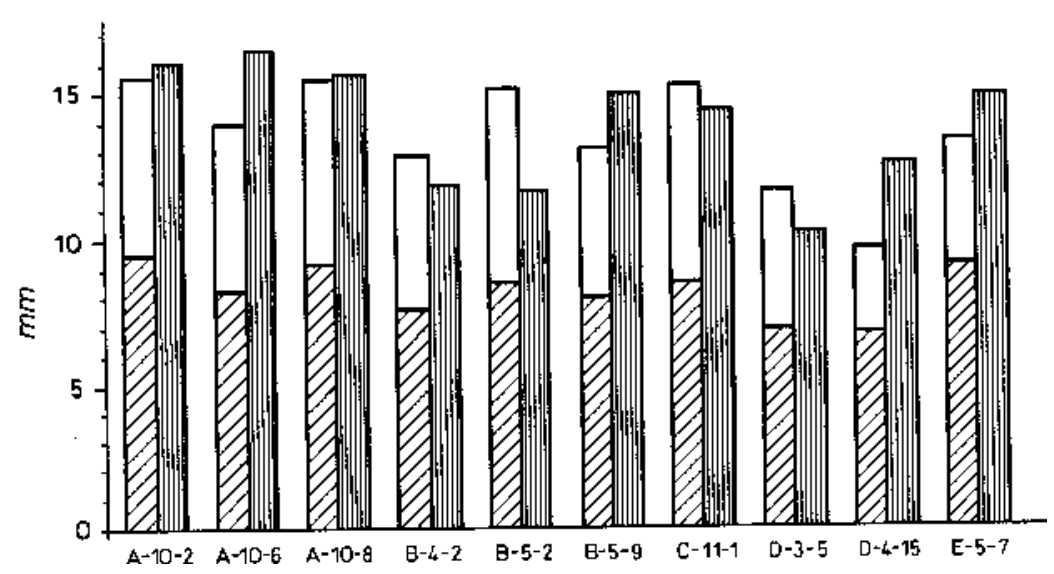

Fig. 3. Pistil level relative to anther position in the flower of the almond selections.

other selections showed similar trends (data not shown). In 1990, the trend was the same, with slightly less significant correlation coefficients.

The differences in flower quality between the two years may be attributed to physiological and environmental effects. Nutrition can be an important determinant of apple (Malus domestica Borkh.) flower quality (Williams, 1965). Differences among cultivars probably also reflect genetic differences (Welkerling
The same is not true for C-11-1, an openpollinated seedling of 'Tuono', because its isozyme bands (Bernad and Socias i Company, 1994) show that it cannot have resulted from self-pollination. 'Tuono' has a high level of flower sterility (Socias i Company, 1983) and this trait is present in most of its offspring (Barahona and Socias i Company, 1988). The percentage of twin flowers, more constant between years (Socias i Company, 1983), reflects genetic differences among the selections. A high proportion of sterile flowers is a negative trait in the evaluation of an almond selection, since high sets are required for commercial crops (Kester and Griggs, 1959). However, both sterility and bud density must be considered in evaluating selections for productivity.

Sterile flowers tend to open later. Also, twin flowers, which exhibit higher percentages of sterility than single ones, open later. This tendency may reflect the fact that fertile flowers are predominantly single, are initiated earlier, have better nutrition, and develop ahead of flowers of lower quality, thus opening earlier (Socias i Company and Felipe, 1993). This relationship suggests that the critical period for crop setting is early flowering, when fertile flowers are predominant.

Stigma-anther position. The stigma relative to anther position is shown in Fig. 3 as the mean levels of the stigma and the upper and lower anthers, as measured from pistil base. Measurements were taken at anthesis because pistil elongation was absent in these selections during bloom (Ben-Njima and Socias i Company, 1995). In four selections (A-10-6, B-59, D-4-15, and E-5-7), the stigma was well above the upper anther, making natural autogamy morphologically difficult. In two other selections, A-10-2 and A-10-8, the stigma was just above the upper anthers, and there may even have been some contact. The four remaining selections, B-4-2, B-5-2, C-11-1, and D-3-5, show ample possibilities for stigmaanther contact and, therefore, for natural selfpollination.

The position of the stigma relative to the anthers is critical for self-pollination in the absence of pollinating insects, as self-compatibility alone is not enough for ensuring a crop in commercial orchards (Godini et al., 1992; Lane, 1979; Socias i Company and Felipe, 1992a). Self-pollination may be possible with three selections, B-4-2, B-5-2, and D-3-5, because of their flower morphology and their self-compatibility. Selection C-11-1, although having favorable flower morphology, does not possess a sufficient level of self-compatibility (Ben-Njima and Socias i Company, 1995).

These results show how the onset of flowering is especially important because fertile flowers open earlier. This finding acquires particular relevance when selecting pollinators for self-incompatible cultivars, but it is also important for self-compatible almond cultivars, which further require a proper flower morphology for natural autogamy. All these traits need to be evaluated to ensure a good fruit set in the absence of pollinating insects. 


\section{Literature Cited}

Barahona, M. and R. Socias i Company. 1988. Esterilidad floral en distintas descendencias de almendro. III Congreso Soc. Española Ciencias Hort., Puerto de la Cruz (Tenerife) 15-22 Oct. 1988, p. 119.

Ben-Njima, N. and R. Socias i Company. 1995. Characterization of some self-compatible almonds. I. Pollen tube growth. HortScience 30:318-320.

Bernad, D. and R. Socias i Company. 1994. Caracterización morfológica y bioquímica de algunas selecciones autocompatibles de almendro. Info. Técnica Econ. Agraria 90V(2):103-110.

Blanco, A. and R. Socias i Company. 1988. Caída de frutos en el melocotonero de carne amarilla dura 'Sudanell-1'. Investigaciones Agraria, Prod. Veg. 3:45-57.

Felipe, A. 1977. Epocas de floración en variedades de almendro. Ann. Inst. Nacional Investigaciones Agraria, Ser. Prod. Veg. 7:105-112.

Felipe, A. and R. Socias i Company. 1985. L'amélioration génétique de l'amandier à Saragosse. Options Méditerr. CIHEAM/IAMZ 85/I:9-14.

Godini, A., L. de Palma, and M. Palasciano. 1992. Role of self-pollination and reciprocal stigma/ anthers position on fruit set of eight self-compatible almonds. HortScience 27:887-889.

Grasselly, C., P. Crossa-Raynaud, G. Olivier, and H. Gall. 1981. Transmission du caractère d'autocompatibilité chez l'amandier (Amygdalus communis). Options Méditerr. CIHEAM/IAMZ 81/I:71-75.

Hill, S.J., D.W. Stephenson, and B.K. Taylor. 1985. Almond pollination studies: Pollen production and viability, flower emergence and cross-pollination tests. Austral. J. Expt. Agr. 25:697-704.

Kester, D.E. and W.H. Griggs. 1959. Fruit setting in the almond: The effect of cross-pollinating various percentages of flowers. Proc. Amer. Soc. Hort. Sci. 74:206-213.

Lane, W.D. 1979. Pollination of self-fertile sweet cherry. J. Hort. Sci. 54:87-89.

Severini, M., G. Tonna, and F. Cardillo. 1986. Computer model of fruit trees flowering. Acta Hort. 184:87-94.

Socias i Company, R. 1983. Flower sterility in almond. Acta Hort. 139:69-74.

Socias i Company, R. 1990. Breeding self-compatible almonds. Plant Breeding Rev. 8:313-338.

Socias i Company, R. 1992. Dinámica de la floración y cuajado en el almendro 'Guara'. Info. Técnica Econ. Agraria 88V(3):193-199.

Socias i Company, R. and A.J. Felipe. 1992a. Self- compatibility and autogamy in 'Guara'almond. J. Hort. Sci. 67:313-317.

Socias i Company, R. and A.J. Felipe. 1992b. Almond: A diverse germplasm. HortScience 27:717-718, 863 .

Socias i Company, R. and A.J. Felipe. 1993. Flower quality and fruit quality in almond: Conflicting objectives? Eucarpia Fruit Breeding Section Mtg., 30 Aug.-3 Sept. 1993, Wädenswill/ Einsiedeln, Switzerland.

Socias i Company, R., D.E. Kester, and M.V. Bradley. 1976. Effects of temperature and genotype on pollen tube growth of some self-incompatible and self-compatible almond cultivars. J. Amer. Soc. Hort. Sci. 101:490-493.

Tabuenca, M.C., M. Mut, and J. Herrero. 1972. Influencia de la temperatura en la época de floración del almendro. Ann. Estac. Expt. Aula Dei 11:378-395

Weinbaum, S.A. 1985. Role of natural self-pollination in self-fruitfulness of almond. Scientia Hort. 27:295-302.

Welkerling, E.M.L. and I.A. Onorati. 1956. Pistilos mal formados en flores de damasco: Su posible origen genético. Rev. Investigaciones Agraria Buenos Aires 10:107-111.

Williams, R.R. 1965. The effect of summer nitrogen application on the quality of apple blossom. J. Hort. Sci. 40:31-41. 